\title{
Isotope Tracing of Long-Term Cadmium Fluxes in an Agricultural Soil
}

\author{
${ }_{2}$ Mahdiyeh Salmanzadeh, ${ }^{* \dagger}{ }^{\dagger}$ Adam Hartland, ${ }^{\dagger}$ Claudine H. Stirling, ${ }^{\ddagger}$ Megan R. Balks, ${ }^{\dagger}$ Louis A. Schipper, \\ ${ }_{3}$ Chaitanya Joshi, ${ }^{\S}$ and Ejin George ${ }^{\ddagger}$ \\ $4{ }^{\dagger}$ Environmental Research Institute, School of Science, University of Waikato, Private Bag 3105, Hamilton 3240, New Zealand \\ 5 Department of Chemistry and Centre for Trace Element Analysis, University of Otago, PO Box 56, Union Place, Dunedin New \\ 6 Zealand \\ $7{ }^{\S}$ Department of Mathematics \& Statistics, University of Waikato, Private Bag 3105, Hamilton 3240, New Zealand
}

9 ABSTRACT: Globally widespread phosphate fertilizer applica-

10 tions have resulted in long-term increases in the concentration of 11 cadmium $(\mathrm{Cd})$ in soils. The accumulation of this biotoxic, and 12 bioaccumulative metal presents problems for the management of 13 soil-plant-animal systems, because the magnitude and direction of 14 removal fluxes (e.g., crop uptake, leaching) have been difficult to 15 estimate. Here, Cd isotopic compositions $\left(\delta^{114 / 110} \mathrm{Cd}\right)$ of archived 16 fertilizer and soil samples from a 66 year-long agricultural field 17 trial in Winchmore, New Zealand, were used to constrain the Cd 18 soil mass balance between 1959 and $2015 \mathrm{AD}$, informing future 19 soil Cd accumulation trajectories. The isotopic partitioning of soil $20 \mathrm{Cd}$ sources in this system was aided by a change in phosphate

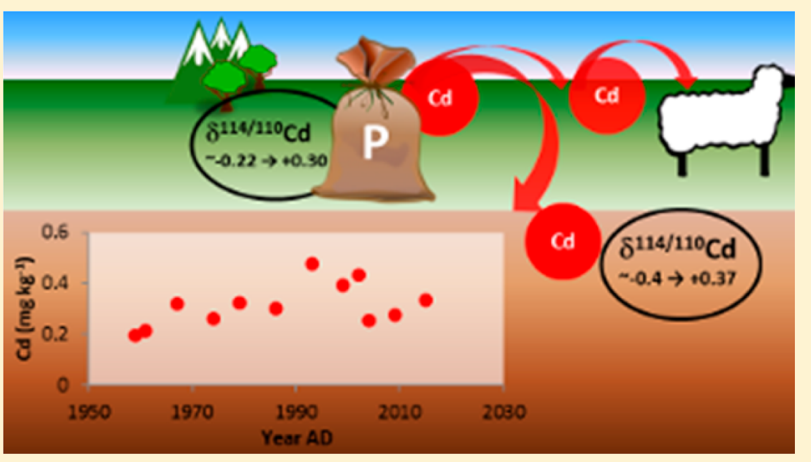
source rocks in $1998 \mathrm{AD}$, and a corresponding shift in fertilizer isotope composition. The dominant influence of mixing between isotopically distinct $\mathrm{Cd}$ end-members was confirmed by a Bayesian modeling approach. Furthermore, isotope mass balance modeling revealed that Cd removal processes most likely increased in magnitude substantially between 2000 and 2015 AD, implying an increase in Cd bioaccumulation and/or leaching over that interval. Natural-abundance stable isotopes are introduced here as a powerful tool for tracing the fate of $\mathrm{Cd}$ in agricultural soils, and potentially the wider environment.

\section{INTRODUCTION}

28 Cadmium $(\mathrm{Cd})$ is a harmful metal that has accumulated in 29 agricultural soils, mainly as a result of phosphate fertilizer 30 applications. $^{1-5}$ Cadmium is a natural contaminant in 31 phosphate source rocks ${ }^{6}$ which persists in fertilizers and can 32 accumulate in soils, plants and higher organisms. In $1997 \mathrm{AD}$, 33 responding to concerns over $\mathrm{Cd}$ accumulation in agricultural 34 soils, the New Zealand (NZ) fertilizer industry changed the 35 main source of phosphate fertilizers from Nauru (guano36 derived) phosphorite (about $450 \mathrm{mg} \mathrm{Cd} \mathrm{kg}^{-1} \mathrm{P}$ ) to a mixture of 37 new sources including Moroccan source rocks, with the effect 38 of lowering $\mathrm{Cd}$ concentrations in fertilizers. Since $1997 \mathrm{AD}$, 39 fertilizers produced in NZ have had no more than $280 \mathrm{mg} \mathrm{Cd}$ $40 \mathrm{~kg}^{-1} \mathrm{P}^{7,8}$

41 Research on long-term $\mathrm{Cd}$ accumulation trends in soils 42 benefits from field trials run over several decades with 43 continuity of land-management practice. A recent study 44 addressing $\mathrm{Cd}$ concentration in soils from the long-term 45 Winchmore field trial in New Zealand showed that the rate of ${ }_{46} \mathrm{Cd}$ accumulation started to reach a plateau in the period since $47 \sim 2000 \mathrm{AD}^{9}{ }^{9}$ This indicated that post $2000 \mathrm{AD}, \mathrm{Cd}$ inputs in 48 fertilizers were lower than outputs from the soil zone (leaching, 49 plant uptake). However, the extent to which the soil Cd burden (after $2000 \mathrm{AD}$ ) was from historical or recent fertilizer 50 applications remained in question.

Stable isotope ratio analysis is a powerful tool for the source 52 identification of environmental contaminants, assuming that 53 end-members are isotopically distinct and isotope fractionations 54 are small and/or well constrained. This approach is increasingly 55 being applied to the study of the origin, and environmental 56 history of heavy metals and other anthropogenic contami- 57 nants, ${ }^{10,11}$ including in atmospheric aerosols, ${ }^{12,13}$ water, ${ }^{14-16} 58$ sediment ${ }^{17-20}$ and soil ${ }^{14,21-26}$ and even materials as diverse as 59 meteorites and lunar soil. ${ }^{27,28}$ Cadmium stable isotopes are 60 being more routinely applied to the study of cadmium's 61 environmental mobility and fate, ${ }^{29}$ and can also inform the 62 biogeochemistry of the soil-plant system including plant- 63 uptake of $\mathrm{Cd},{ }^{11}$ which has been shown to fractionate $\mathrm{Cd} 64$ between soil and wheat, with preferential accumulation of 65 lighter isotopes over heavier isotopes in roots relative to grain. 66

Difficulties in the management of $\mathrm{Cd}$ accumulation in 67 agricultural soils are currently compounded by uncertainty over 68

Received: February 15, 2017

Revised: June 2, 2017

Accepted: June 6, 2017

Published: June 6, 2017 
69 the sources of $\mathrm{Cd}$, since routine $\mathrm{Cd}$ monitoring is a 70 comparatively recent phenomenon. It is also difficult to 71 evaluate the effect that management strategies have on the 72 accumulation of $\mathrm{Cd}$ and delineate whether changes in the total $73 \mathrm{Cd}$ pool reflect historical, or more recent $\mathrm{Cd}$ additions. 74 Therefore, the objective of this research was to evaluate the 75 utility of $\mathrm{Cd}$ stable isotope ratios as a tracer of $\mathrm{Cd}$ sources in 76 soil samples from the long-term Winchmore field trial, where 77 annual superphosphate (a manufactured $\mathrm{P}$ fertilizer) applica78 tions began in ca. 1949 and have continued to the present day. 79 Based on the $\mathrm{Cd}$ isotopic composition of the control site 80 subsoil (approximating native soil-Cd), topsoil samples from 81 the Winchmore archive, as well as historical and recent 82 fertilizers, we calculated the changing proportion of $\mathrm{Cd}$ in 83 Winchmore topsoil through time using a Bayesian mixing 84 model. This approach was extended using an isotope-enabled ${ }_{85} \mathrm{Cd}$ mass balance to evaluate the influence of fertilizer inputs 86 and removal mechanisms on $\mathrm{Cd}$ accumulation through time.

\section{MATERIALS AND METHODS}

88 Study site. Soil samples were taken from the Winchmore 89 research farm on the Canterbury Plains of the South Island, 90 New Zealand $\left(43^{\circ} 47 \mathrm{~S}, 171^{\circ} 48 \mathrm{E}, 167 \mathrm{~m}\right.$ above sea level, 91 annual rainfall $\left.740 \mathrm{~mm} / \mathrm{yr}^{9}\right)$. The soil at Winchmore is Lismore 92 Stony Silt loam (Orthic Brown [New Zealand], Udic 93 Ustochrept [USDA]) which is developed from moderately 94 weathered greywacke loess. ${ }^{9}$ The selected physical and 95 chemical characteristics of the soil including $\mathrm{pH}$, organic 96 carbon, nitrogen and soil texture were reported by Condron 97 and Goh. ${ }^{30}$ The soil is developed on outwash plains formed by 98 the weathering of the Southern Alps, which are dominantly 99 composed of greywacke sandstone gravels, stratigraphically 100 defined as Paleosols. ${ }^{31}$ Two different trials were conducted at 101 Winchmore: long-term fertilizer and long-term irrigation trials 102 that were established in 1952 and 1949, respectively. For the 103 irrigation trial, $250 \mathrm{~kg} \mathrm{ha}^{-1}$ of superphosphate was applied 104 annually, but irrigation was applied at different soil moisture 105 trigger values (dryland treatment with no irrigation, $10 \%$ 106 moisture and $20 \%$ moisture). Soil samples were selected from 107 the top $7.5 \mathrm{~cm}$ of the irrigation trial (dryland treatment; plot 108 15) from 1959, 1961, 1967, 1974, 1979, 1993, 1999, 2002 109 (Waikato University Archive), 2004, and 2009 (courtesy of 110 Richard McDowell, AgResearch), and an additional sample was 111 collected in 2015. One control plot soil sample from 112 unfertilized (native) soil was taken from the subsurface layer $113(25-30 \mathrm{~cm}$ depth) of an adjacent paddock which has the same 114 geology and was expected to have a similar chemical 115 composition to the topsoils (before fertilization). Phosphate 116 rock and fertilizer samples were obtained from Ballance Agri117 Nutrients Ltd. (Tauranga, New Zealand), including samples 118 from Nauru and Christmas Island (main sources of phosphorite 119 for phosphate fertilizer manufacture prior to $1997 \mathrm{AD}^{8}$ ), 120 fertilizer from the mid-1980s, and archived fertilizers from 121 1998, 2000, 2001, 2005, 2007, 2009, 2011, 2013, and 2015 (all 122 used in the Winchmore trials) were also analyzed. Isotopic 123 analyses were performed on two independently chemically 124 processed aliquots of each sample of soil, phosphorite or 125 fertilizer, with the exception of fertilizers from 1998, 2001, 1262005 , 2011, and 2013, for which just one sample was analyzed 127 for isotopic composition.

128 Cadmium Concentration and Isotopic Composition 129 Analysis of Soils and Fertilizers. All samples were dried and 130 sieved $(<2 \mathrm{~mm})$ and then digested using a method described in
Salmanzadeh et al. ${ }^{32}$ with some minor modifications: The 131 reagents were pipetted out of the polypropylene tube without 132 any filtration and transferred to clean polypropylene tubes for 133 ICP-MS analysis at the University of Waikato. The samples 134 were not filtered in order to avoid any introduction of Cd from 135 filter papers. $^{33,34}$ To avoid any contamination, sample 136 preparation was carried out in a class-100 laminar flow hood. 137 Also, all sample tubes and vials were thoroughly acid-washed in 138 clean reagent grade $\mathrm{HCl}$ at room temperature, then in 50\% 139 quartz distilled $\mathrm{HCl}$ (overnight). Finally all lab-ware was rinsed 140 thoroughly (5 times with Milli-Q deionized water). All acids 141 were purified in a Savillex DST-1000 acid purification system to 142 parts-per-trillion (ppt)-grade (Cd blank <100 ppt). Cadmium 143 concentration was determined by using a quadrupole ICP-MS 144 (PerkinElmer Elan, Waltham, MA) at University of Waikato, 145 New Zealand following calibration using NIST-traceable 146 standards (Inorganic Ventures, Christiansburg, VA, USA). 147

After measuring the concentration of $\mathrm{Cd}$, aliquots of each 148 sample digest, corresponding to approximately $50 \mathrm{ng}$ of $\mathrm{Cd}, 149$ were transferred to University of Otago, New Zealand for 150 isotopic analysis following a double-spike method (full methods 151 provided in Supporting Information (SI) Methods 1, Table 152 S1).

Cadmium isotopic composition is generally expressed as the 154 deviation of ${ }^{114} \mathrm{Cd} /{ }^{110} \mathrm{Cd}$ ratio of a sample with respect to the 155 ${ }^{114} \mathrm{Cd} /{ }^{110} \mathrm{Cd}$ composition of a standard in parts per-thousand ${ }_{156}$ $\left(\delta^{114 / 110} \mathrm{Cd}\right)($ eq 1$)$. In this study, Cd isotopic composition was 157 measured by multiple-collector ICP-MS (MC-ICPMS) using a 158 $\mathrm{Nu}$ Plasma-HR instrument (Nu Instruments Ltd., U.K.) and 159 methods modified from previous protocols. ${ }^{35,36}$ A DSN 100160 desolvating nebulizer fitted with a $\sim 100 \mu \mathrm{L} / \mathrm{min}$ perfluor- 161 oalkoxy (PFA) nebulizer was used as the sample introduction 162 system. The NIST $3108 \mathrm{Cd}$ isotope standard sourced from the 163 National Institute of Science and Technology (NIST), U.S., 164 was used as the "zero delta" normalizing standard. ${ }^{37}$ Repeat 165 measurements of the NIST 3108 standard give rise to an 166 external reproducibility of $0.04 \delta$ that is comparable to the 2 SE 167 internal precision associated with individual measurements (SI 168 Figure S1). Using these protocols, standard reference materials 169 give values that are identical, within error, to certified 170 values. ${ }^{35-38}$

$$
\delta^{114 / 110} \mathrm{Cd}=\left[\frac{\left({ }^{114} \mathrm{Cd} /{ }^{110} \mathrm{Cd}\right)_{\text {sample }}}{\left({ }^{114} \mathrm{Cd} /{ }^{110} \mathrm{Cd}\right)_{\text {NIST3108 }}}-1\right] \cdot 1000
$$

All Cd concentrations reported in this study were 173 determined by isotope dilution using eq 2 :

$$
\begin{aligned}
& {[\mathrm{Cd}]_{\text {sample }}=} \\
& \frac{\left(\frac{{ }^{114} \mathrm{Cd}}{111} \mathrm{Cd}\right.}{{ }^{11}}-\left(\frac{{ }^{114} \mathrm{Cd}}{{ }^{111} \mathrm{Cd}}\right)_{\text {spike }} \\
& \left(\frac{{ }^{114} \mathrm{Cd}}{111} \mathrm{Cd}\right)_{\text {sample }}-\left(\frac{11^{11} \mathrm{Cd}}{{ }^{111} \mathrm{Cd}}\right)_{\text {mixture }} \cdot \frac{\text { mass of spike }}{\text { mass of sample }} \cdot \frac{\left.{ }^{111} \mathrm{Cd}\right]_{\text {spike }}}{\text { fraction of }{ }^{11} \mathrm{Cd} \text { in the sample }}
\end{aligned}
$$

where ${ }^{114} \mathrm{Cd} /{ }^{111} \mathrm{Cd}_{\text {mixture, }},{ }^{114} \mathrm{Cd} /{ }^{111} \mathrm{Cd}$ sample, and 176 ${ }^{114} \mathrm{Cd} /{ }^{111} \mathrm{Cd}_{\text {spike }}$ are the ${ }^{114} \mathrm{Cd} /{ }^{111} \mathrm{Cd}$ ratios of the spike-sample 177 mixture, sample and double spike, respectively, after correction 178 for the instrumental mass bias, while $\left[{ }^{111} \mathrm{Cd}\right]_{\text {spike }}$ is the 179 concentration of ${ }^{111} \mathrm{Cd}$ in the double spike and $[\mathrm{Cd}]_{\text {sample }}$ is 180 the Cd concentration of the sample.

Sequential Extraction Method. In an attempt to 182 constrain the $\mathrm{Cd}$ speciation in the Winchmore soil system, 183 the topsoil collected in 2015 (two replicates) was sequentially 184 
185 extracted following the method of Sun et al. ${ }^{39}$ (full method 186 provided in SI Methods 2, Table S2).

187 Bayesian Mixing Model. Stable isotope data combined 188 with a Bayesian modeling approach have been used before to 189 estimate the contribution of multiple sources of elements in 190 environmental samples. ${ }^{15,40,41}$ However, this is the first time 191 this approach has been used for the Cd stable isotope system. 192 We used an open source linear isotopic mixing Bayesian 193 modeling strategy devised by Arendt, Aciego and Hetland ${ }^{14}$ to 194 estimate the fractional contribution of different sources of Cd 195 through time. Matlab 2013 was used with code introduced by 196 Arendt, Aciego and Hetland ${ }^{14}$ with some modifications: Arendt, 197 Aciego and Hetland ${ }^{14}$ defined the code based on the isotope 198 ratios of two different elements (for example $\delta^{18} \mathrm{O}$ and $\delta \mathrm{D}$ ), but 199 we instead defined the model based on the isotope ratio of a 200 single element $\left(\delta^{114 / 110} \mathrm{Cd}\right)$. The original Matlab code was 201 configured for three different sources, but we defined only two 202 sources for pre-2000 soils and three sources for post-2000 soils. $203 \mathrm{pH}$ Adsorption Edge Experiment. $\mathrm{pH}$ is the most 204 important variable controlling the adsorption of metals to soil 205 surfaces. $^{42}$ Therefore, a $\mathrm{pH}$ adsorption edge experiment was 206 carried out to determine the $\mathrm{pH}$-dependency of $\mathrm{Cd}$ adsorption 207 on Winchmore topsoil. This experiment followed the method 208 by Lee et al. ${ }^{43}$ (full method provided in SI Methods 3, Figure 209 S3). Ideally, this can inform the potential of Cd to adsorb to 210 soil under varying solution $\mathrm{pH}$.

211 Cadmium Balance (CadBal) Model. A cadmium mass 212 balance model ( $\mathrm{CadBal}$ ) has been available since 2005 in New 213 Zealand, to estimate the potential accumulation of $\mathrm{Cd}$ in $\mathrm{NZ}$ 214 soils. ${ }^{7,9}$ This model estimates the accumulation of $\mathrm{Cd}$ based on 215 input data including the initial $\mathrm{Cd}$ concentration, farm and soil 216 type, soil dry bulk density, fertilizer application rate, leaching, 217 erosion, and atmospheric accession. We used this model to 218 estimate the future concentration (up to $2030 \mathrm{AD}$ ) of $\mathrm{Cd}$ in 219 topsoil and to compare our results with those of $\mathrm{McDowell}^{9}$ 220 who studied the same site and reported a trend toward 221 stabilizing $\mathrm{Cd}$ concentrations in the period after $2000 \mathrm{AD}$. $222 \mathrm{CadBal}$ was used to estimate the concentration of $\mathrm{Cd}$ through 223 time based on four scenarios and using two sets of input data 224 (Table 1, SI Table S4).

225 Isotope Mass Balance Using CadBal Output. An isotope 226 mass balance approach was taken to constrain the importance
Table 1. Mean Concentrations and Isotopic Compositions of $\mathrm{Cd}$ in Topsoil $(0-7.5 \mathrm{~cm})$, Fertilizer and Phosphorite Samples, And the Control Subsurface Soil $(25-30 \mathrm{~cm})$

\begin{tabular}{lcc}
\multicolumn{1}{c}{ sample } & $\mathrm{Cd}\left(\mathrm{mg} \mathrm{kg}^{-1}\right)^{a}$ & $\delta^{114 / 110} \mathrm{Cd} \pm 2 \mathrm{SE}$ \\
native (unfertilized) subsoil & 0.02 & $-0.33 \pm 0.04$ \\
topsoil 1959 & 0.16 & $0.27 \pm 0.04$ \\
topsoil 1961 & 0.22 & $0.10 \pm 0.04$ \\
topsoil 1967 & 0.24 & $0.20 \pm 0.04$ \\
topsoil 1974 & 0.23 & $0.20 \pm 0.04$ \\
topsoil 1979 & 0.25 & $0.23 \pm 0.05$ \\
topsoil 1986 & 0.29 & $0.14 \pm 0.03$ \\
topsoil 1993 & 0.40 & $0.12 \pm 0.04$ \\
topsoil 1999 & 0.35 & $0.15 \pm 0.04$ \\
topsoil 2002 & 0.35 & $0.16 \pm 0.05$ \\
topsoil 2004 & 0.29 & $0.09 \pm 0.05$ \\
topsoil 2009 & 0.29 & $0.08 \pm 0.03$ \\
topsoil 2015 & 0.30 & $0.15 \pm 0.03$ \\
fertilizer 1980s & 31.8 & $0.25 \pm 0.04$ \\
fertilizer 1998 & 26.4 & $0.10 \pm 0.05$ \\
fertilizer 2000 & 27.0 & $0.18 \pm 0.04$ \\
fertilizer 2001 & 14.6 & $0.01 \pm 0.05$ \\
fertilizer 2005 & 21.0 & $-0.11 \pm 0.05$ \\
fertilizer 2007 & 23.3 & $-0.11 \pm 0.04$ \\
fertilizer 2011 & 15.4 & $-0.11 \pm 0.06$ \\
fertilizer 2013 & 20.6 & $-0.12 \pm 0.05$ \\
fertilizer 2015 & 8.27 & $-0.17 \pm 0.03$ \\
nauru phosphorite & 96.4 & $0.22 \pm 0.04$ \\
Christmas Island phosphorite & 38.0 & $0.12 \pm 0.04$ \\
\hline
\end{tabular}

${ }^{a}$ Instrumental uncertainties are $\pm 0.9 \%$ (2 SE).

of fertilizer inputs to topsoils relative to losses via cropping (i.e., 227 grass growth and grazing) and leaching to groundwater. The 228 input and output terms in this mass balance were constrained 229 using CadBal (see previous section and I Methods 4) which 230 generates loss terms for these vectors. CadBal is able to 231 generate loss terms for erosion and input terms for atmospheric 232 deposition, but these were neglected because of their very low 233 magnitude (see SI Table S4). The resulting mass balance 234 equation is given below (eq 3 ).

$$
[\mathrm{Cd}]_{n+1_{\text {soil }}} \times \delta_{n+1_{\text {soil }}}=\left([\mathrm{Cd}]_{n}+\delta_{n}\right)_{\text {soil }}+\left([\mathrm{Cd}]_{n_{\text {fert }}}+\delta_{n_{\text {fert }}}\right)_{\text {inputs }}-\left([\mathrm{Cd}]_{n_{\text {corp }}} \times \delta_{n_{\text {crop }}}+[\mathrm{Cd}]_{n_{\text {teach }}} \times \delta_{n_{\text {teach }}}\right)_{\text {outputs }}
$$

237

$238 \delta_{n}$ is the isotope ratio of the compartment in per mil, and $[\mathrm{Cd}]_{\mathrm{n}}$ 239 is $\mathrm{Cd}$ concentration and derived as follows (eq 4):

$$
\begin{aligned}
{[C d]_{n+1}=} & {[C d]_{n}+\left(\mathrm{Cd}_{\text {input }} \mathrm{ha}^{-1}-\mathrm{Cd}_{\text {output }} \mathrm{ha}^{-1}\right)_{n} / } \\
& \left(\text { bulk density } \times \text { depth ha }{ }^{-1}\right)
\end{aligned}
$$

241 Isotope fractionation in each input and output term is 242 calculated by multiplying the $\delta$ value (e.g., $\delta_{n \text { leach }}$ ) by an 243 appropriate $\alpha$ value (e.g., $\alpha_{\text {soil-leachate }}$ ), where $\alpha$ defines the 244 equilibrium partitioning of $\mathrm{Cd}$ isotopes between the reactant 245 and product (eq 5).

$246 \quad \delta_{a}+1000=\left(\delta_{b}+1000\right) \times \alpha_{a-b}$

247 This modeling utilized $\alpha$ values taken from Wiggenhauser et $248 \mathrm{al}^{11}$ which were selected on the basis of relevance (i.e., 249 similarity to soil properties). However, the available literature 250 on Cd isotope fractionation factors do not currently cover soil- grass and soil-water partitioning. Because of this deficiency we 251 have approximated these terms using data from soil-wheat 252 systems and extractable soil solutions $\left(\mathrm{Ca}\left(\mathrm{NO}_{3}\right)_{2}\right),{ }^{11}$ respec- 253 tively.

RESULTS AND DISCUSSION 255

Cd Composition of Soils, Fertilizers and Source Rocks. 256 The Cd concentration and $\mathrm{Cd}$ isotopic composition of soils, 257 fertilizers and phosphate rocks are presented in Table 1 . Where 258 data are available for two independently processed aliquots of 259 the same sample (i.e., true replicate measurements of the soil), 260 both $\mathrm{Cd}$ concentration and $\mathrm{Cd}$ isotopic composition are 261 reported as the mean of the two replicate analyses with the two 262 standard error of the mean values, calculated using the method 263 of Conway et al. ${ }^{44}$ Corresponding data for each individual 264 analysis is given in the SI (see Table S3). Otherwise, data is 265 
266 reported as the mean value and 2 SE uncertainty for a single 267 analysis, as per standard analytical protocols.

268 The concentrations of $\mathrm{Cd}$ in Nauru and Christmas Island 269 rocks (Table 1) were in the range of previously reported 270 concentrations $\left(86-100 \mathrm{mg} \mathrm{kg}^{-1}\right.$ for Nauru and $31-56 \mathrm{mg}$ $271 \mathrm{~kg}^{-1}$ for Christmas Island phosphorite ${ }^{3,8,45-47}$ ). Cadmium 272 concentrations in Winchmore plot- 15 topsoils increased across 273 the period $1959-2000 \mathrm{AD}$ from ca. 0.16 to $0.35 \mathrm{mg} \mathrm{kg}^{-1}$ 274 (Figure 1a), replicating the change in concentration reported
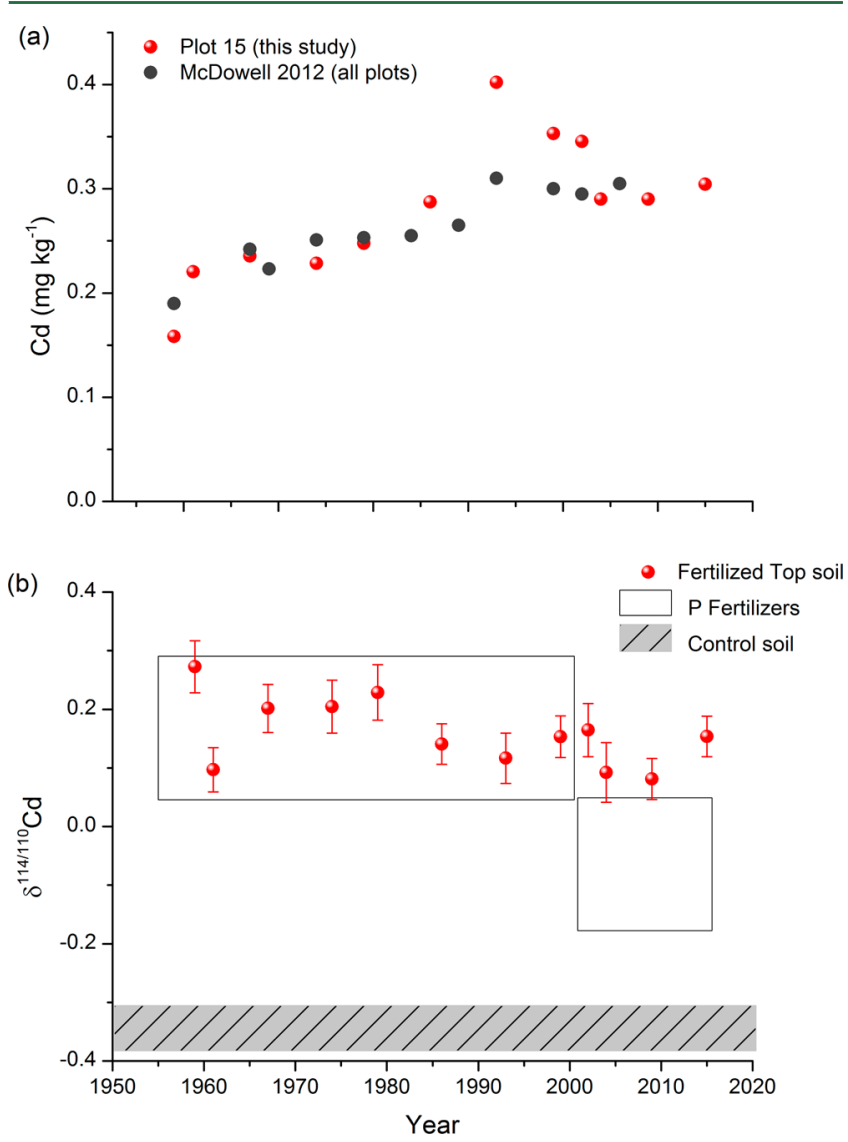

Figure 1. Time series of $\mathrm{Cd}$ in topsoil samples from Winchmore (a) data from plot 15 (dryland treatment-this study; error bars are 2 SE range) and data from $\mathrm{McDowell}^{9}$ representing the mean concentration of $\mathrm{Cd}$ in topsoil in all irrigation trial plots (b) the Cd isotope ratios of fertilized soils over the period 1959-2015 (error bars show the 2 SE range of analytical uncertainty in $\delta^{114 / 110} \mathrm{Cd}$ values), blank rectangles represent the $2 \mathrm{SE}$ range of isotope ratios from $\mathrm{P}$ fertilizer sources before and after $2000 \mathrm{AD}$, and the hatched rectangle shows the $2 \mathrm{SE}$ range of isotope ratios of the control soil.

275 across the whole site by McDowell. ${ }^{9}$ The $\mathrm{Cd}$ isotope ratios of 276 fertilized soil samples were enriched relative to the control site 277 subsoil throughout this interval, and were in the range of $278 \delta^{114 / 110} \mathrm{Cd}$ in pre-2000 (including $2000 \mathrm{AD}$ ) fertilizers and 279 phosphorite samples (Table 1, Figure 1); which also fall within 280 the typical range of sedimentary rocks excluding polluted and 281 industrial samples (ranging from -0.4 to $+0.4 \delta^{114 / 110} \mathrm{Cd}$ ) ${ }^{48}$ and 282 loess deposits (ranging from -0.45 to 0.34 ). ${ }^{49}$ Cadmium 283 isotope ratios in the fertilizer and phosphorite samples studied 284 here were all well within these ranges (Table 1).

285 The ranges of $\delta^{114 / 110} \mathrm{Cd}$ in Winchmore topsoils from these 286 time series are comparable to the $\delta^{114 / 110} \mathrm{Cd}$ ratios characteristic 287 of pre-2000 AD fertilizer samples. Topsoils were enriched in ${ }^{288}{ }^{114} \mathrm{Cd}$ relative to the lower $\delta^{114 / 110} \mathrm{Cd}$ of the control site subsoil, the latter being most consistent with $\delta^{114 / 110} \mathrm{Cd}$ observed in 289 some wind-blown (loess) deposits. ${ }^{48}$ It was necessary to use the 290 subsoil from the control site at Winchmore to approximate the 291 native soil Cd composition, because Cd in the topsoil of the 292 control site was likely to have been impacted by windblown 293 cross-contamination from adjacent fertilized paddocks and by 294 translocation of fertilizer-derived Cd by grazing ruminants. 295

The Cd isotope results from Winchmore topsoils indicate 296 that fertilizer applications from $\sim 1950 \mathrm{AD}$ onward substantially 297 affected the $\delta^{114 / 110} \mathrm{Cd}$ of topsoils, such that by 1959 (first data 298 point in our time series) the topsoil Cd concentration and Cd 299 isotope ratio had been substantially modified from the natural 300 situation (approximated by our control (Table 1)). Depleted 301 $\delta^{114 / 110} \mathrm{Cd}$ values, presumably characteristic of the original 302 (unfertilized) topsoil, were not observed in the earliest samples 303 from our time series (1959 AD) which were taken a full nine 304 years after the onset of fertilizer application, by which time we 305 argue $\mathrm{Cd}$ concentrations and isotope ratios had been shifted 306 substantially. Overall, the Cd isotope ratios of all fertilized soil 307 samples were closest to the $\mathrm{Cd}$ isotopic compositions of pre- 308 $2000 \mathrm{AD}$ fertilizers (Figure 1), suggesting that pre-2000 AD 309 fertilizers strongly dominated the Cd budget in the Winchmore 310 soils even after $2000 \mathrm{AD}$. However, this assessment does not 311 account for potential fractionation effects in either fertilizers or 312 soil samples, and this needs to be evaluated before sources can 313 be attributed based on $\mathrm{Cd}$ isotope data.

314

Cadmium Isotope Fractionation in Soil and Fertilizer 315 Samples. To produce a single superphosphate fertilizer (as 316 used at Winchmore throughout the entire trial), finely ground 317 phosphate rocks, largely consisting of fluorapatite 318 $\left(\mathrm{Ca}_{5}\left(\mathrm{PO}_{4}\right)_{3} \mathrm{~F}\right)$, are reacted with sulfuric acid and during this 319 process all of the $\mathrm{Cd}$ originally present in the phosphate rock is 320 retained within the fertilizer. ${ }^{50-52}$ Due to the high volatility and 321 low boiling point $\left(765^{\circ} \mathrm{C}\right)$ of $\mathrm{Cd},{ }^{29,48,53}$ large $(\sim 0.6 \%$ level $) 322$ isotope fractionations of $\mathrm{Cd}$ can occur during high-temperature 323 industrial processes such as smelting and combustion. ${ }^{54-56} 324$ However, Cd isotopic fractionation characteristics of the 325 aforementioned high-temperature industrial processes, do not 326 appear to occur during phosphate fertilizer manufacture which 327 is carried out under low thermal conditions. This is borne out 328 by a comparison between the $\delta^{114 / 110} \mathrm{Cd}$ of pre-2000 $\mathrm{AD} 329$ fertilizers and their Nauru and Christmas Island source rocks 330 (Table 1; Figure 1). The data assembled here indicates that 331 phosphate fertilizers retain an $\delta^{114 / 110} \mathrm{Cd}$ composition con- 332 sistent with the guano-derived phosphorites of Nauru and 333 Christmas Island. ${ }^{59}$ This indicates that either no $\mathrm{Cd}$ isotopic 334 fractionation occurs during industrial processing, or that all $\mathrm{Cd} 335$ is quantitatively transferred from the phosphate source rock to 336 the superphosphate fertilizer so that no net isotopic 337 fractionation of $\mathrm{Cd}$ is observed.

338

A large degree of $\mathrm{Cd}$ isotopic fractionation in soil samples 339 can occur due to biogeochemical processes in soils, ${ }^{11}$ therefore 340 the potential for in situ fractionation processes must be 341 considered before mixing models can be used for source 342 identification. Processes within agricultural soils that could 343 cause $\mathrm{Cd}$ isotope fractionation include 1. Redox processes: 344 elements usually occurring with one oxidation state (such as 345 $\mathrm{Cd}$ ) in natural systems tend to exhibit smaller isotopic 346 variations in comparison to other metals with multiple 347 oxidation states. ${ }^{10}$ However, Cd has a strong affinity for 348 sulfides, forming in the presence of free $\mathrm{H}_{2} \mathrm{~S}$ under euxinic 349 (anoxic and sulphidic, rather than anoxic, suboxic or oxic) 350 conditions, so $\mathrm{Cd}$ is strongly redox-sensitive in this sense and 351 
352 potentially fractionates during CdS formation. This is unlikely 353 to be an issue in the free-draining soils of Canterbury, where 354 sulfate reduction is inhibited by atmospheric gas exchange. 2 . 355 Adsorption processes: reactions with organic matter and soil 356 mineral surfaces have potential to induce $\mathrm{Cd}$ isotopic 357 fractionation. ${ }^{10}$ Simulations of $\mathrm{Cd}$ isotopic fractionation in 358 hydrothermal fluids between $\mathrm{Cd}$ species (cadmium hydroxide, 359 cadmium nitrates, cadmium hydrates, cadmium chloride, and 360 cadmium hydrosulfides) do not support a strong role for $\mathrm{Cd}$ 361 speciation, ${ }^{54,58}$ although adsorption of $\mathrm{Cd}$ to synthetic 362 birnessite ( $\mathrm{Mn}$ oxyhydroxide) has been shown to cause a 363 small fractionation effect at low ionic strength. ${ }^{59,60} 3$. Biological 364 cycling: plant uptake has been shown to cause $\mathrm{Cd}$ isotope 365 fractionation $^{11}$ with diffusion and adsorption being largely 366 responsible for $\mathrm{Cd}$ fractionation at the root-solution inter367 face $^{10,61}$ In addition, permil-level Cd isotopic fractionation (by 368 adsorption of lighter isotopes) has been observed during $\mathrm{Cd}$ 369 uptake by phytoplankton (unicellular plants in the sunlit surface 370 ocean). ${ }^{36,44,62,63}$ 4. Natural weathering processes can also lead 371 to $\mathrm{Cd}$ isotopic fractionation. ${ }^{64}$

372 The enriched $\mathrm{Cd}$ isotopic composition of fertilized soils 373 compared to the native soil show that there was some potential 374 that the $\mathrm{Cd}$ isotope ratios in fertilized soils could have been 375 fractionated due to biogeochemical or weathering processes in 376 the soil zone. ${ }^{11,65,66}$ The fractionation of $\mathrm{Cd}$ isotopes within the 377 fertilized soil samples during biological assimilation (i.e., by in 378 situ bacterial communities, uptake by plant roots, or trans379 location in infiltrating soil water) is assessed in the section on $380 \mathrm{Cd}$ mass balance modeling (Mass Balance Modeling of Cd).

381 Source Identification of $\mathbf{C d}$. The following analysis takes a 382 simple mixing approach and neglects potential fractionation 383 effects, which are expected to be damped by the significant 384 input signal of fertilizer-derived $\mathrm{Cd}$. This latter point is 385 addressed by mass balance modeling in a later section Mass 386 Balance Modeling of $\mathrm{Cd}$ ). Large changes in the $\delta^{114 / 110} \mathrm{Cd}$ of 387 superphosphate are expected to have imparted changes in 388 residual soil isotope values of a magnitude proportional to the 389 fractional accumulation of $\mathrm{Cd}$ (based on the analysis of 390 fertilizers (Table 1)).

391 Cadmium isotopic differences between end-members can be 392 readily delineated using a $\delta^{114 / 110} \mathrm{Cd}$ versus $1 / \mathrm{Cd}$ mixing 393 diagram (Figure 2a). ${ }^{26,29,49}$ Soils did not align along a single 394 line (Figure 2a) which indicates that $\mathrm{Cd}$ in fertilized soil 395 samples originated from at least three different sources (i.e., 396 native soil, pre-2000 $\mathrm{AD}$ fertilizer and post-2000 $\mathrm{AD}$ fertilizer), 397 and also may have been affected by in situ processes. ${ }^{29}$ The $398 \delta^{114 / 110} \mathrm{Cd}$ of control soil did not follow a trendline with the 399 fertilized soil samples, and was well isolated from the soils in 400 terms of both $\mathrm{Cd}$ concentration and $\mathrm{Cd}$ isotope ratio (Figure $4012 a)$.

402 Bayesian Attribution of Soil Cd Sources. Based on the 403 clear difference between the $\mathrm{Cd}$ isotopic end-members 404 identified in this study, a binary mixing model was applied 405 for pre-2000 $\mathrm{AD}$ soil samples, and a three-source mixing model 406 was applied for post-2000 AD soil samples (Table 2). Different 407 strategies were considered in selecting the end-members to 408 calculate the fractional contribution of different sources through 409 time (Table 2). Given the relatively small sample size in our set $410(N=26)$ we acknowledge that our approach is constrained and 411 would be enhanced by additional replicate measurements. 412 However, the Bayesian approach followed provides the best 413 means of estimating the accompanying errors.

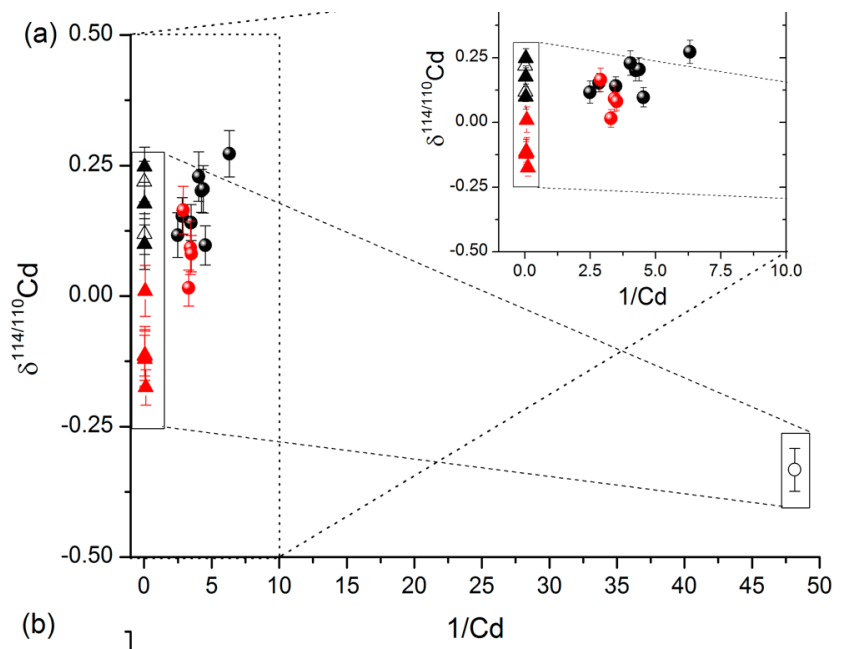

(b)

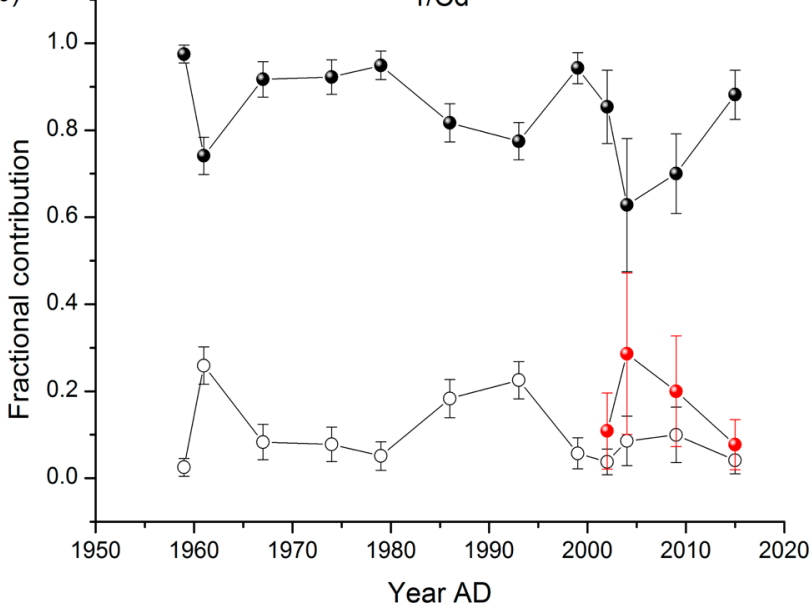

Figure 2. Source partitioning of $\mathrm{Cd}$ in Winchmore plot 15 soil samples (a) $\mathrm{Cd}$ isotopic composition versus inverse $\mathrm{Cd}$ concentration $(\mathrm{mg}$ $\mathrm{kg}^{-1}$ ) of pre-2000 $\mathrm{AD}$ (black circle) and post-2000 $\mathrm{AD}$ (red circle) soil samples defined by control soil (open circle), phosphate rocks (open triangle), pre-2000 $\mathrm{AD}$ fertilizers (black triangle), and post-2000 $\mathrm{AD}$ fertilizers (red triangle) (error bars are \pm 2 SE from the mean); (b) Fractional contribution of different sources of $\mathrm{Cd}$ in Winchmore soil samples based on a Bayesian Cd isotope mixing model for pre-2000 $\mathrm{AD}$ fertilizers (black circle), post-2000 AD fertilizers (red circle), and control soil (open circle).

The fractional contribution of different sources (Figure 2b) 414 was calculated using a Bayesian mixing model (Arendt, Aciego, 415 and Hetland ${ }^{14}$ ) which uses the variances of end-member 416 compositions to compute the uncertainty inherent in the 417 fractional contribution of sources. The model assumed that the 418 uncertainties associated with the Cd isotopic compositions of 419 end-members are uncorrelated, normally distributed, and 420 represented by the two standard errors of the measurements. 421 It was also assumed that there are only three possible 422 contributing sources in any one modeled mixture. For pre- 423 $2000 \mathrm{AD}$ soil samples, two possible contribution sources were 424 considered, since phosphate fertilizers were mainly sourced 425 from a single Pacific island (Nauru) during this time. For post- 426 $2000 \mathrm{AD}$ soils, three different sources were identified (Table 2). 427 The detailed assumptions and limitations inherent in the 428 modeling approach can be found in Arendt, Aciego, and 429 Hetland. ${ }^{14}$ These authors showed that the estimations of the 430 fractional contribution of different sources are more precise if 431 the end-member isotopic compositions are distinct from one 432 another, which is the case in the pre-2000 AD Cd isotopic data 433 
Table 2. Different End-Members Considered for Calculation of the Fractional Contribution of Cd Sources through Time in Topsoil Samples

\begin{tabular}{lcll}
\multicolumn{1}{c}{ soil } & endmember-1 & \multicolumn{1}{c}{ endmember-2 (pre-2000 fertilizer) } & endmember-3 (post-2000 fertilizer) \\
$1959-1993$ & native soil & fertilizer 1980s & \\
1999 & native soil & average of fertilizer 1980s and fertilizer 1998 & fertilizer 2001 \\
2002 and 2004 & native soil & average of fertilizers 1980s, 1998 and 2000 & average of fertilizers 2001, 2005 and 2007 \\
2009 & native soil & average of fertilizers 1980s, 1998 and 2000 & average of fertilizers 2001, 2005, 2007, 2011, 2013, 2015 \\
2015 & native soil & average of fertilizers 1980s, 1998 and 2000 & \\
\hline
\end{tabular}

434 (Figure 2a). However, because the pre- and post-2000 AD 435 fertilizers were closer in composition than the native soil, this 436 contributed to greater uncertainty in the model. Despite this 437 source of uncertainty, the Bayesin mixing model demonstrates 438 that $\mathrm{Cd}$ in the topsoil samples predominantly corresponds to 439 inputs from Nauru-derived (pre-2000 AD) fertilizers. This is 440 particularly clear in the $2015 \mathrm{AD}$ analysis. We can conclude that $441 \mathrm{Cd}$ derived from Nauru continues to predominate in the soil up 442 to the present day.

443 The mixing model outputs (Figure 2b) show from $2000 \mathrm{AD}$ 444 toward the present, fertilizer $\delta^{114 / 110} \mathrm{Cd}$ became increasingly 445 isotopically distinct from the Nauru-derived fertilizers, thus 446 increasing the confidence of the estimation of source 447 contributions in the mixing model (Figure $2 \mathrm{~b}$ ). The estimate 448 from $2015 \mathrm{AD}$ shows that residual $\mathrm{Cd}$ in the Winchmore soil to 449 the present day is dominated by historical fertilizer inputs. 450 Hence, variability in the estimated fractional contribution 451 between 2000 and $2015 \mathrm{AD}$ can be rationalized as a possible 452 statistical artifact arising from the close similarity of end453 member $\delta^{114 / 110} \mathrm{Cd}$ values through this period. According to the 454 mixing model the time-averaged fractional contribution of each 455 source was about $10 \%$ for native soil, about $80 \%$ for pre- 2000 $456 \mathrm{AD}$ fertilizers and about $17 \%$ for post-2000 $\mathrm{AD}$ fertilizers 457 (Figure $2 \mathrm{~b}$ ). The results are therefore consistent with $\mathrm{Cd}$ in 458 Winchmore soil samples being primarily derived from Nauru 459 fertilizers, which is consistent with previous studies that have 460 shown the typically long residence times of $\mathrm{Cd}$ in soil (e.g., up 461 to 3000 years). ${ }^{67,68}$

462 What Caused the Recent Plateau in Winchmore soil $463 \mathrm{Cd}$ ? $\mathrm{McD}$ owell ${ }^{9}$ documented the recent decline in soil $\mathrm{Cd}$ 464 accumulation at Winchmore. This study has extended $465 \mathrm{McD}$ owell's analysis and has confirmed that $\mathrm{Cd}$ concentration 466 in the topsoil has indeed plateaued. Furthermore, Cd isotopic 467 analysis identifies pre-2000 $\mathrm{AD}$ fertilizers as the predominant 468 source of $\mathrm{Cd}$ in the system. One possible conclusion based on 469 this observation is that recent applications of $\mathrm{Cd}$ are not 470 tending to accumulate. It is possible that this newer $\mathrm{Cd}$ is 471 unable to effectively compete for adsorption sites in the soil 472 matrix, thereby displacing the older Nauru-derived Cd. An 473 alternative hypothesis is that in situ fractionation of $\mathrm{Cd}$ isotopes 474 by pasture growth and/or leaching are modifying the observed 475 isotope compositions (Figure $1 \mathrm{~b}$ ).

476 The analysis of sequential topsoil extracts confirmed that 477 only a relatively small proportion $(37 \%)$ of the total Cd was 478 readily exchangeable (displacement by $\mathrm{Mg}^{2+}$ at $\mathrm{pH}$ 7) (SI 479 Figure S2). Therefore, excluding hydrological changes 480 associated with climate over the period, we identify two 481 probable drivers of the concentration plateau:

482 Reduced Cd inputs associated with the industry Cd 483 management strategy

484 Increases in the loss of $\mathrm{Cd}$ from the soil zone

485 As $\mathrm{McDowell}^{9}$ has documented, $\mathrm{pH}$ in the soil from the 486 fertilizer trial at Winchmore changed throughout the series, with shifts between $\mathrm{pH} \sim 6.0$ and $\sim 5.6$ over the period of soil 487 Cd stabilization (1990-2015 AD). In order to evaluate the 488 possible impact of soil $\mathrm{pH}$ changes, a $\mathrm{Cd} \mathrm{pH}$ adsorption edge 489 experiment was completed. This showed that the $\mathrm{pH} 490$ dependency of $\mathrm{Cd}$ adsorption is likely to be most strongly 491 modulated between pH values of 3.5 and 5.3 (SI Figure S3). 492 The $\mathrm{pH}$ of the control site subsoil in $2015 \mathrm{AD}$ was determined 493 at $\mathrm{pH} 5.4$ and plot 15 topsoil from the same year had a $\mathrm{pH}$ of 494 5.2. The $\mathrm{Cd}$ adsorption efficiency of soil through time was 495 estimated based on linear regression $\left(R^{2}=0.96\right)$ between \%Cd 496 adsorbed and $\mathrm{pH}$ in the adsorption edge experiment between 497 $\mathrm{pH}$ values of 5.3 and 8 (SI Figure S3). The estimated Cd 498 adsorption efficiency change corresponded to a shift of slightly 499 greater than $2 \%$ (between $\mathrm{pH} 5.4$ and 6.0). Over the same 500 interval (1990-2015 AD), the Cd concentrations in plot 15501 topsoil (this study) declined by $\sim 25 \%$. This is therefore 502 inconsistent with a $\mathrm{pH}$ control on $\mathrm{Cd}$ adsorption capacity. In 503 order to better understand the mechanisms of $\mathrm{Cd}$ accumulation 504 and loss at Winchmore, a mass balance modeling approach was 505 taken.

506

Mass Balance Modeling of $\mathbf{C d}$. McDowell $^{9}$ showed that 507 reduced loading of $\mathrm{Cd}$ from fertilizer is sufficient to explain the 508 observed $\mathrm{Cd}$ accumulation trends at Winchmore assuming 509 lower total $\mathrm{Cd}$ in superphosphate fertilizer applications. Our 510 analysis of fertilizer samples from the period 1998-2015 (Table 511 1) demonstrates that fertilizer Cd was actually higher $(204.0 \pm 512$ $66.8 \mathrm{mg} \mathrm{Cd} \mathrm{kg}^{-1} \mathrm{P} ; n=8$ ) during this period than that assumed 513 by McDowell previously ${ }^{9}$ ( $\left.140 \pm 60.62 \mathrm{mg} \mathrm{Cd} \mathrm{kg}^{-1} \mathrm{P} ; n=3\right)$. 514 This difference in total concentration resulted in a large 515 overprediction of soil $\mathrm{Cd}$ accumulation during the period post- 516 $2000 \mathrm{AD}$ based on our better-constrained input data (Figure $517 \mathrm{f} 3$ 3a).

$518 \mathrm{f} 3$

The results of $\mathrm{Cd}$ mass balance modeling completed in this 519 study and in $\mathrm{McDowell}^{9}$ demonstrate that the fertilizer Cd 520 concentration data of $\mathrm{McD}$ owell best represented the period of 521 early Cd accumulation between 1949 and 1998, whereas the 522 detailed determinations of fertilizer Cd between 1998 and 2015523 $\mathrm{AD}$ in this study provide improved constraint on $\mathrm{Cd} 524$ accumulation trends post-2000 AD (Figure 3a; see SI Table 525 S4 for details of modeling scenarios). The second scenario 526 (blue curve (Figure 3a)) overestimated Cd accumulation over 527 the entire record because only two fertilizer samples for the 528 period pre-2000 $\mathrm{AD}$ were considered (just one fertilizer sample 529 for period of 1949-1998), whereas $\mathrm{McDowell}^{9}$ used five pre- 530 $2000 \mathrm{AD}$ fertilizers. The third scenario (red curve (Figure 3a)) 531 combined McDowell's pre-1998 AD fertilizer concentration 532 data (isotope ratio from our pre-1998 $\mathrm{AD}$ samples) and the 533 post-1998 AD fertilizers characterized in this study. This third 534 modeling scenario provides an improved fit to topsoil 535 concentrations and isotope ratios through the period 1959- 536 $2000 \mathrm{AD}$ (Figure 3a,b). However, important discrepancies were 537 observed between the modeled and measured data after 2000538 $\mathrm{AD}$. Most importantly, the third scenario model output 539 


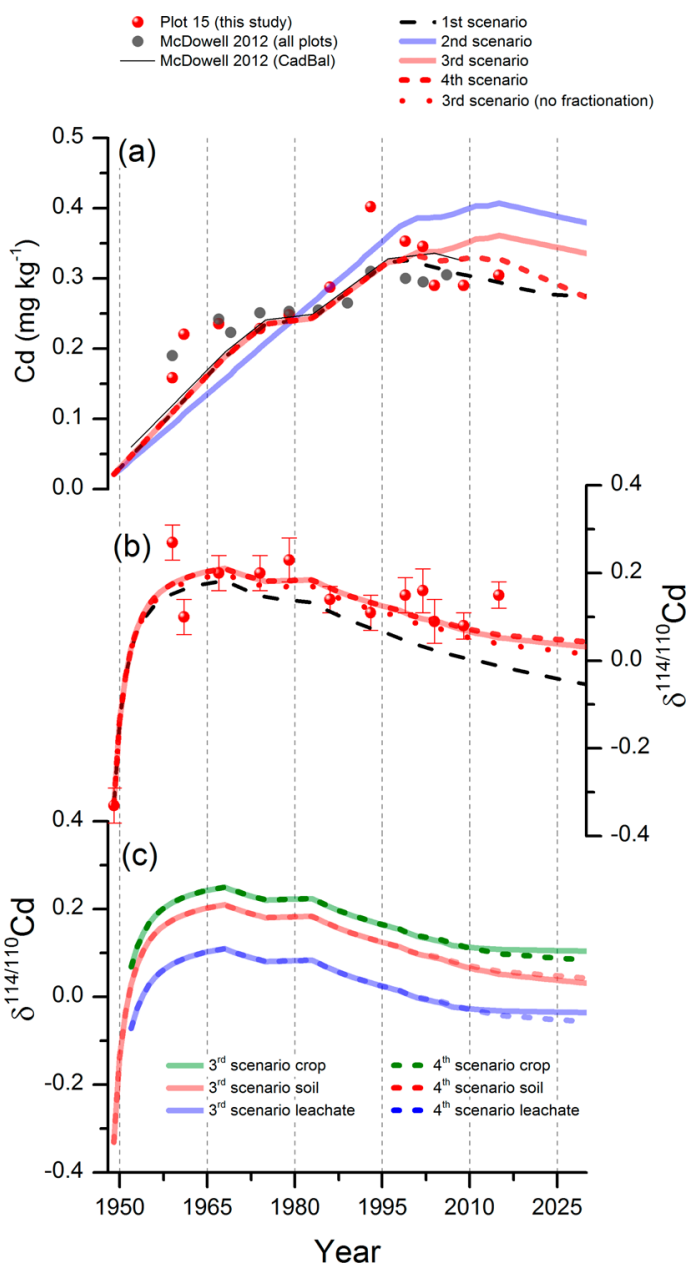

Figure 3. Results of $\mathrm{Cd}$ mass balance modeling in CadBal for the period of topsoil fertilization at Winchmore including a prediction up to the year $2030 \mathrm{AD}$. (a) Cd concentration in Winchmore topsoils (symbols) and the dryland optimized CadBal model outputs (lines); $\left(\right.$ red symbols $=$ this study-plot 15 ; gray symbols $=\mathrm{McDowell}^{9}$ studyaverage of all plots; solid black line $=\mathrm{McDowell}^{9}$ all irrigation plots; black dashed line $=$ Plot 15 , first scenario; blue line $=$ Plot 15 , second scenario; red line $=$ Plot 15 , third scenario; red dashed line $=$ Plot 15 , fourth scenario); (b) Measured and modeled Cd isotope ratios based on CadBal outputs, isotope ratios measured in fertilizers and the fractionation factors of Wiggenhauser et al.; ${ }^{11}$ lines designate modeling scenarios as in (a), red dots are the third scenario with no fractionation ( $\alpha$ factor not applied); (c) modeled scenario 3 (solid) and scenario 4 (dashed) isotope ratios in topsoil (red lines), leachate (blue lines) and pasture (green lines).

540 overpredicted the concentration of $\mathrm{Cd}$ in topsoil in the most 541 recent period (Figure 3a). This overestimation was tested in a 542 fourth scenario, in which the leaching rate was doubled for the 543 post-2000 $\mathrm{AD}$ period. The results of scenario four (SI Table 544 S4) showed a closer correspondence to the measured Plot 15 $545 \mathrm{Cd}$ concentrations, post-2000 AD (red dashed line (Figure $5463 \mathrm{a})$ ). The doubling of $\mathrm{Cd}$ removal by leaching did not 547 substantially alter the modeled soil isotope ratio between the 548 third (red line (Figure 3b)) and fourth scenarios (red dashed 549 line (Figure 3b)).

550 The mass balance modeling results confirm that recent 551 applications of $\mathrm{P}$ fertilizer have not resulted in an accumulation 552 of $\mathrm{Cd}$ consistent with the model boundary conditions (for crop 553 uptake/leaching (SI Table S4)) which gave good agreement for 554 the period prior to $2000 \mathrm{AD}$ (Figure 3a). This implies that removal of $\mathrm{Cd}$ by either leaching or crop uptake has increased 555 during this most recent period. The modeled $\mathrm{Cd}$ isotope data 556 appear to be consistent with this interpretation (Figure 3b). 557 Slightly more enriched values of $\mathrm{Cd}$ isotopes in plot 15 soil 558 (than predicted by scenario 4) may therefore indicate that $\quad 559$

(1) in situ processes acting on Cd may have fractionated the 560 residual $\mathrm{Cd}$ pool toward heavier values than predicted by 561 the $\mathrm{Cd}$ fractionation factors used here (Wiggenhauser et 562 al. $\left.^{11}\right)$; or

(2) Cd from recent fertilizer applications contributed less to 564 the total soil Cd isotope composition than predicted by 565 the model (which assumes perfect mixing).

566

The modeled isotope ratios given in Figure $3 \mathrm{~b}$-c extend to 567 $2030 \mathrm{AD}$ and provide the means to systematically test the 568 process of $\mathrm{Cd}$ accumulation and loss at this site. It would be 569 beneficial to extend the analysis of $\mathrm{Cd}$ isotopes in the future to 570 include $\mathrm{Cd}$ accumulated by pasture and $\mathrm{Cd}$ leached to 571 groundwater. The predicted trend in exchangeable Cd over 572 time is shown in Figure 3c.

Environmental Significance. This study has shown that 574 $\mathrm{Cd}$ isotope ratios in fertilized soils were distinguishable from 575 the control soils and were comparable to the source rocks used 576 in fertilizer manufacture. Cadmium isotopic analysis is therefore 577 a promising tool to trace the fate of fertilizer-derived Cd in the 578 environment beyond the soil zone, provided the influence of 579 possible additional biogeochemical processes that can poten- 580 tially modify the $\mathrm{Cd}$ isotope signals of the soils are well 581 constrained, and that the $\mathrm{Cd}$ isotopic composition and $\mathrm{Cd} 582$ concentration of the native soil are well-known. If the declining 583 trend observed at Winchmore is emblematic of Cd behavior in 584 soil systems elsewhere, it follows that the $\mathrm{Cd}$ is migrating from 585 the soil zone, either through uptake by plants and animals, or 586 by translocation down the soil profile and via erosive losses. 587 Cadmium isotopes may therefore offer the potential to trace 588 this $\mathrm{Cd}$ and monitor its environmental impact, at least in areas 589 where substantial $\mathrm{Cd}$ contamination from other activities is 590 scarce.

591

\section{ASSOCIATED CONTENT}

The Supporting Information is available free of charge on the 594 ACS Publications website at DOI: 10.1021/acs.est.7b00858. 595

Table S1-S4 Figure S1-S3 Supplementary Methods 1- 596 4 Matlab code (PDF)

\section{AUTHOR INFORMATION}

\section{Corresponding Author}

*(M.S.) E-mail: Salmanzadeh.mahdiyeh@gmail.com.

Mahdiyeh Salmanzadeh: 0000-0002-8849-6228

The manuscript was written through contributions of all 604 authors. M.S. completed all laboratory work (column 605 chemistry, extractions etc.) and the Bayesian and isotope 606 mass balance modeling. MC-ICP-MS analyses were conducted 607 by E.G. and C.S. A.H. secured funding, sampled soils from 608 Winchmore, cowrote the final text with M.S., and produced the 609 final versions of the figures for publication. L.S. provided 610 archived Winchmore soil samples. C.J. assisted with Matlab 611 coding. All authors have given approval to the final version of 612 the manuscript. 


\section{Notes}

615 The authors declare no competing financial interest.

\section{ACKNOWLEDGMENTS}

617 This research was funded by the Fertilizer Association of New 618 Zealand under contact number RE.35.1. We are grateful to Ray 619 Moss, Richard McDowell and Ian Power for providing soil and 620 fertilizer samples and Steve Cameron for ICP-MS analyses. 621 Carli. A. Arendt is thanked for helpful guidance on using the 622 Bayesian mixing model. Funding for this research was provided 623 by the Fertiliser Association of New Zealand (Contract 624 RE.35.1).

\section{REFERENCES}

626 (1) Santonen, T.; Aitio, A.; Fowler, B. A.; Nordberg, M., Chapter 8 627 Biological Monitoring and Biomarkers. In Handbook on the Toxicology 628 of Metals; 4th ed; Academic Press: San Diego, 2015; pp 155-171.

629 (2) Gray, C. W.; McLaren, R. G.; Roberts, A. H. C.; Condron, L. M. 630 Solubility, sorption and desorption of native and added cadmium in 631 relation to properties of soils in New Zealand. Eur. J. Soil Sci. 1999, 50 632 (1), 127-137.

633 (3) Loganathan, P.; Hedley, M. J.; Grace, N. D.; Lee, J.; Cronin, S. J.; 634 Bolan, N. S.; Zanders, J. M. Fertiliser contaminants in New Zealand 635 grazed pasture with special reference to cadmium and fluorine - a 636 review. Aust. J. Soil Res. 2003, 41 (3), 501-532.

637 (4) De Boo, W. Cadmium in agriculture. Toxicol. Environ. Chem. 638 1990, 27 (1-3), 55-63.

639 (5) Mann, S. S.; Rate, A. W.; Gilkes, R. J. Cadmium Accumulation in 640 Agricultural Soils in Western Australia. Water, Air, Soil Pollut. 2002, 641141 (1), 281-297.

642 (6) Mar, S. S.; Okazaki, M. Investigation of Cd contents in several 643 phosphate rocks used for the production of fertilizer. Microchem. J. 644 2012, 104, 17-21.

645 (7) Roberts, A. H. C.; Longhurst, R. D. A cadmium balance model for 646 New Zealand pastoral systems; Report prepared for the New Zealand 647 Fertiliser Manufacturer's Research Association: AgResearch, Hamilton, 648 New Zealand, 2005.

649 (8) Cadmium Working Group Report One: Cadmium in New 650 Zeland Agriculture. http://maxa.maf.govt.nz/mafnet/rural-nz/ 651 sustainable-resource-use/land-management/cadmium-in-nz/report652 one/cadmium-report-1.pdf (5 July 2015),

653 (9) McDowell, R. W. The rate of accumulation of cadmium and 654 uranium in a long-term grazed pasture: implications for soil quality. $N$. 655 Z. J. Agric. Res. 2012, 55 (2), 133-146.

656 (10) Wiederhold, J. G. Metal stable isotope signatures as tracers in 657 environmental geochemistry. Environ. Sci. Technol. 2015, 49 (5), 2606. 658 (11) Wiggenhauser, M.; Bigalke, M.; Imseng, M.; Müller, M.; Keller, 659 A.; Murphy, K.; Kreissig, K.; Rehkämper, M.; Wilcke, W.; Frossard, E. 660 Cadmium Isotope Fractionation in Soil-Wheat Systems. Environ. Sci. 661 Technol. 2016, 50 (17), 9223-9231.

662 (12) Félix, O. I.; Csavina, J.; Field, J.; Rine, K. P.; Sáez, A. E.; 663 Betterton, E. A. Use of lead isotopes to identify sources of metal and 664 metalloid contaminants in atmospheric aerosol from mining 665 operations. Chemosphere 2015, 122, 219-226.

666 (13) Lee, P. K.; Yu, S. Lead isotopes combined with a sequential 667 extraction procedure for source apportionment in the dry deposition 668 of Asian dust and non-Asian dust. Environ. Pollut. 2015, 210, 65-75. 669 (14) Arendt, C. A.; Aciego, S. M.; Hetland, E. A. An open source 670 Bayesian Monte Carlo isotope mixing model with applications in Earth 671 surface processes. Geochem., Geophys., Geosyst. 2015, 16 (5), 12746721292.

673 (15) Cable, J.; Ogle, K.; Williams, D. Contribution of glacier 674 meltwater to streamflow in the Wind River Range, Wyoming, inferred 675 via a Bayesian mixing model applied to isotopic measurements. Hydrol. 676 Process. 2011, 25 (14), 2228-2236.

677 (16) Song, S.; Mathur, R.; Ruiz, J.; Chen, D.; Allin, N.; Guo, K.; 678 Kang, W. Fingerprinting two metal contaminants in streams with $\mathrm{Cu}$ isotopes near the Dexing Mine, China. Sci. Total Environ. 2016, 544, 679 677-85. 680

(17) Chae, J. S.; Choi, M. S.; Song, Y. H.; Um, I. K.; Kim, J. G. 681 Source identification of heavy metal contamination using metal 682 association and $\mathrm{Pb}$ isotopes in Ulsan Bay sediments, East Sea, Korea. 683 Mar. Pollut. Bull. 2014, 88 (1-2), 373-82.

684

(18) Gao, B.; Zhou, H.; Liang, X.; Tu, X. Cd isotopes as a potential 685 source tracer of metal pollution in river sediments. Environ. Pollut. 686 2013, 181, 340-343.

(19) Lepak, R. F.; Yin, R.; Krabbenhoft, D. P.; Ogorek, J. M.; 688 DeWild, J. F.; Holsen, T. M.; Hurley, J. P. Use of Stable Isotope 689 Signatures to Determine Mercury Sources in the Great Lakes. Environ. 690 Sci. Technol. Lett. 2015, 2 (12), 335-341.

691

(20) Feng, X.; Foucher, D.; Hintelmann, H.; Yan, H.; He, T.; Qiu, G. 692 Tracing Mercury Contamination Sources in Sediments Using Mercury 693 Isotope Compositions. Environ. Sci. Technol. 2010, 44 (9), 3363-3368. 694

(21) Watmough, S. A.; Hughes, R. J.; Hutchinson, T. C. 206Pb/ 695 207Pb Ratios in Tree Rings as Monitors of Environmental Change. 696 Environ. Sci. Technol. 1999, 33 (5), 670-673.

697

(22) Phillips, D. L.; Koch, P. L. Incorporating Concentration 698 Dependence in Stable Isotope Mixing Models. Oecologia 2002, 130699 (1), 114-125.

(23) Wong, S. C.; Li, X. D.; Zhang, G.; Qi, S. H.; Min, Y. S. Heavy 701 metals in agricultural soils of the Pearl River Delta, South China. 702 Environ. Pollut. 2002, 119 (1), 33-44.

(24) Kersten, M.; Xiao, T.; Kreissig, K.; Brett, A.; Coles, B. J.; 704 Rehkämper, M. Tracing Anthropogenic Thallium in Soil Using Stable 705 Isotope Compositions. Environ. Sci. Technol. 2014, 48 (16), 9030- 706 9036.

(25) Chrastný, V.; Čadková, E.; Vaněk, A.; Teper, L.; Cabala, J.; 708 Komárek, M. Cadmium isotope fractionation within the soil profile 709 complicates source identification in relation to $\mathrm{Pb}-\mathrm{Zn}$ mining and 710 smelting processes. Chem. Geol. 2015, 405, 1-9.

(26) Wen, H.; Zhang, Y.; Cloquet, C.; Zhu, C.; Fan, H.; Luo, C. 712 Tracing sources of pollution in soils from the Jinding $\mathrm{Pb}-\mathrm{Zn}$ mining 713 district in China using cadmium and lead isotopes. Appl. Geochem. 714 2015, 52, 147-154.

(27) Wombacher, F.; Rehkämper, M.; Mezger, K.; Bischoff, A.; 716 Münker, C. Cadmium stable isotope cosmochemistry. Geochim. 717 Cosmochim. Acta 2008, 72 (2), 646-667.

(28) Schediwy, S.; Rosman, K. J. R.; de Laeter, J. R. Isotope 719 fractionation of cadmium in lunar material. Earth Planet. Sci. Lett. 720 2006, 243 (3-4), 326-335.

(29) Cloquet, C.; Carignan, J.; Libourel, G.; Sterckeman, T.; Perdrix, 722 E. Tracing source pollution in soils using cadmium and lead isotopes. 723 Environ. Sci. Technol. 2006, 40 (8), 2525.

(30) Condron, L. M.; Goh, K. M. Effects of long-term phosphatic 725 fertilizer applications on amounts and forms of phosphorus in soils 726 under irrigated pasture in New Zealand. J. Soil Sci. 1989, 40 (2), 383- 727 395.

(31) Leamy, M. L.; Milne, J. D. G.; Pullar, W. A.; Bruce, J. G. 729 Paleopedology and soil stratigraphy in the New Zealand Quaternary 730 succession. N. Z. J. Geol. Geophys. 1973, 16 (3), 723-744. 731

(32) Salmanzadeh, M.; Balks, M. R.; Hartland, A.; Schipper, L. A. 732 Cadmium accumulation in three contrasting New Zealand soils with 733 the same phosphate fertilizer history. Geoderma Regional 2016, 7 (3), 734 271-278.

(33) John, M. K.; VanLaerhoven, C. J. Error in cadmium 736 determinations due to adsorption by filter papers. Bull. Environ. 737 Contam. Toxicol. 1976, 15 (2), 211-213.

(34) Matoug, I. O. M. Study of metals contamination in different 739 filter papers. IOSR J. Environ. Sci., Toxicol. Food Technol. 2013, 3 (5), 740 59-61.

(35) Gault-Ringold, M.; Stirling, C. H. Anomalous isotopic shifts 742 associated with organic resin residues during cadmium isotopic 743 analysis by double spike MC-ICPMS. J. Anal. At. Spectrom. 2012, 27744 (3), 449-459.

(36) Gault-Ringold, M.; Adu, T.; Stirling, C. H.; Frew, R. D.; Hunter, 746 K. A. Anomalous biogeochemical behavior of cadmium in subantarctic 747 
748 surface waters: Mechanistic constraints from cadmium isotopes. Earth 749 Planet. Sci. Lett. 2012, 341-344, 94-103.

750 (37) Abouchami, W.; Galer, S. J. G.; Horner, T. J.; Rehkamper, M.; 751 Wombacher, F.; Xue, Z. C.; Lambelet, M.; Gault-Ringold, M.; Stirling, 752 C. H.; Schonbachler, M.; Shiel, A. E.; Weis, D.; Holdship, P. F. A 753 common reference material for Cadmium isotope studies - NIST SRM 754 3108. Geostand. Geoanal. Res. 2013, 37 (1), 5.

755 (38) Boyle, E. A.; John, S.; Abouchami, W.; Adkins, J. F.; Echegoyen756 Sanz, Y.; Ellwood, M.; Flegal, A. R.; Fornace, K.; Gallon, C.; Galer, S.; 757 Gault-Ringold, M.; Lacan, F.; Radic, A.; Rehkamper, M.; Rouxel, O.; 758 Sohrin, Y.; Stirling, C.; Thompson, C.; Vance, D.; Xue, Z.; Zhao, Y. 759 GEOTRACES IC1 (BATS) contamination-prone trace element 760 isotopes $\mathrm{Cd}, \mathrm{Fe}, \mathrm{Pb}, \mathrm{Zn}, \mathrm{Cu}$, and $\mathrm{Mo}$ intercalibration. Limnol. 761 Oceanogr.: Methods 2012, 10 (9), 653-665.

762 (39) Sun, F.; Xie, M.; Wu, C. Quick sequential procedure for 763 speciation analysis of heavy metals in soils by supersonic extraction. 764 Chem. Speciation Bioavailability 2005, 17 (4), 137-146.

765 (40) Moore, J. W.; Semmens, B. X. Incorporating uncertainty and 766 prior information into stable isotope mixing models. Ecol. Lett. 2008, 76711 (5), 470-480.

768 (41) Parnell, A. C.; Inger, R.; Bearhop, S.; Jackson, A. L. Source 769 partitioning using stable isotopes: coping with too much variation. 770 PLoS One 2010, 5 (3), e9672.

771 (42) Sposito, G. The Surface Chemistry of Soils. Oxford University 772 Press: New York, 1984.

773 (43) Lee, S. Z.; Allen, H. E.; Huang, C. P.; Sparks, D. L.; Sanders, P. 774 F.; Peijnenburg, W. J. G. M. Predicting soil-water partition coefficients 775 for cadmium. Environ. Sci. Technol. 1996, 30 (12), 3418-3424.

776 (44) Conway, T. M.; Rosenberg, A. D.; Adkins, J. F.; John, S. G. A 777 new method for precise determination of iron, zinc and cadmium 778 stable isotope ratios in seawater by double-spike mass spectrometry. 779 Anal. Chim. Acta 2013, 793, 44-52.

780 (45) Reiser, R.; Simmler, M.; Portmann, D.; Clucas, L.; Schulin, R.; 781 Robinson, B. Cadmium concentrations in new zealand pastures: 782 Relationships to soil and climate variables. J. Environ. Qual. 2014, 43, 783 917-925.

784 (46) Syers, J. K.; Mackay, A. D.; Brown, M. W.; Currie, L. D. 785 Chemical and physical characteristics of phosphate rock materials of 786 varying reactivity. J. Sci. Food Agric. 1986, 37 (11), 1057-1064.

787 (47) Williams, C. H.; David, D. J. The effects of superphosphate on 788 cadmium content of soils and plants. Aust. J. Soil Res. 1973, 11, 43-56. 789 (48) Wombacher, F.; Rehkämper, M.; Mezger, K.; Münker, C. Stable 790 isotope compositions of cadmium in geological materials and 791 meteorites determined by multiple-collector ICPMS. Geochim. 792 Cosmochim. Acta 2003, 67 (23), 4639-4654.

793 (49) Schmitt, A.-D.; Galer, S. J. G.; Abouchami, W. Mass-dependent 794 cadmium isotopic variations in nature with emphasis on the marine 795 environment. Earth Planet. Sci. Lett. 2009, 277 (1-2), 262-272.

796 (50) Amalhay, M.; Roberts, T. L. SYMPHOS 2013 - 2nd 797 International Symposium on Innovation and Technology in the 798 Phosphate IndustryCadmium and Phosphorous Fertilizers: The Issues 799 and the Science. Procedia Eng. 2014, 83, 52-59.

800 (51) Ballnace Agri-Nutrients Cadmium in Fertilizers; New Zealand. $801 \mathrm{https}: / /$ www.google.co.nz/url? $\mathrm{sa}=\mathrm{t} \& \mathrm{rct}=\mathrm{j} \& \mathrm{q}=\& \mathrm{esrc}=\mathrm{s} \&$ source $=$ $802 \mathrm{w}$ e b \& c d $=3 \& \mathrm{c}$ a d $=\mathrm{rj}$ a $\&$ u a c $t=8 \& \mathrm{v}$ e $d=$

803 OahUKEwjdspXBqZXOAhWEFpQKHY8QBL0QFgguMAI\&url= $804 \mathrm{~h} \mathrm{t} \mathrm{t} \mathrm{p} \mathrm{\%} 3$ A \% 2 F \% $2 \mathrm{Fw} w \mathrm{w}$. b a 11 a n c e.co.

805 nz\%2F \%2Fmedia\%2FBALLANCE-WEB\%2FOur-Science\%2FFact806 Sheets\%2Fpdf\%2FBallance-fact-sheet--Cadmium-in-fertilisers-O80715035 . a shx\%3 F la \% 3 D e n \& us g = A F Qj C N GW 808 w O J 0 X 4 r g m C A t c 6 L 3 q w G R 18 Z 3 g \& s i g $2=$ 809 ctceFkXRfWRZPbwBsck8Hghttps://www.google.co.nz/url?sa=t\&rct= $810 j \& q=\& e s r c=s \&$ source $=w e b \& c d=3 \& c a d=r j a \& u a c t=8 \& v e d=$ 811 0ahUKEwjdspXBqZXOAhWEFpQKHY8QBL0QFgguMAI\&url= $812 \mathrm{~h} \mathrm{t} \mathrm{t} \mathrm{p} \mathrm{\%} 3 \mathrm{~A} \% 2 \mathrm{~F} \% 2 \mathrm{Fwww}$. b a 11 a n c e.co.

$813 \mathrm{nz} \% 2 \mathrm{~F} \sim \% 2 \mathrm{Fmedia} \% 2 \mathrm{FBALLANCE}-\mathrm{WEB} \% 2 \mathrm{FOur}$-Science\%2FFact814 Sheets\%2Fpdf\%2FBallance-fact-sheet--Cadmium-in-fertilisers-O81515035 . a shx\% 3 F la \% 3 D en \& u s g = A F Qj C N GW - w O J 0 X 4 rg m C A t c 6 L 3 q w G R 18 Z 3 g \& s ig $2=816$ ctceFkXRfWRZPbwBsck8Hg, 2014.

(52) Rothbaum, H. P.; Goguel, R. L.; Johnston, A. E.; Mattingly, G. 818 E. G. Cadmium accumulation in soils from long-continued 819 applications of superphosphate. J. Soil Sci. 1986, 37 (1), 99-107. 820

(53) Fegley, B., Cosmochemistry. In Encyclopedia of Planetary Science; 821 Springer Netherlands: Dordrecht, 1997; pp 169-177.

822

(54) Yang, J. L.; Li, Y. B.; Liu, S. Q.; Tian, H. Q.; Chen, C. Y.; Liu, J. 823 M.; Shi, Y. L. Theoretical calculations of Cd isotope fractionation in 824 hydrothermal fluids. Chem. Geol. 2015, 391, 74.

(55) Shiel, A. E.; Weis, D.; Orians, K. J. Evaluation of zinc, cadmium 826 and lead isotope fractionation during smelting and refining. Sci. Total 827 Environ. 2010, 408 (11), 2357-68.

(56) Martinkova, E.; Chrastny, V.; Francova, M.; Sipkova, A.; Curik, 829 J.; Myska, O.; Mizic, L. Cadmium isotope fractionation of materials 830 derived from various industrial processes. J. Hazard. Mater. 2016, 302, 831 114-9.

(57) Standing Committee on Agriculture and Resource Manage- 833 ment-Ruminants Subcommittee. Feeding Standards for Australian 834 Livestock: Ruminants; CSIRO Publications: Australia, 1990.

(58) Loganathan, P.; Vigneswaran, S.; Kandasamy, J.; Naidu, R. 836 Cadmium sorption and desorption in soils: A review. Crit. Rev. Environ. 837 Sci. Technol. 2012, 42 (5), 489-533.

(59) Wasylenki, L. E.; Swihart, J. W.; Romaniello, S. J. Cadmium 839 isotope fractionation during adsorption to $\mathrm{Mn}$ oxyhydroxide at low 840 and high ionic strength. Geochim. Cosmochim. Acta 2014, 140, 212- 841 226.

(60) Horner, T. J.; Schönbächler, M.; Rehkämper, M.; Nielsen, S. G.; 843 Williams, H.; Halliday, A. N.; Xue, Z.; Hein, J. R. Ferromanganese 844 crusts as archives of deep water Cd isotope compositions. Geochem., 845 Geophys., Geosyst. 2010, 11, 1-10.

(61) Wei, R.; Guo, Q.; Wen, H.; Liu, C.; Yang, J.; Peters, M.; Hu, J.; 847 Zhu, G.; Zhang, H.; Tian, L.; Han, X.; Ma, J.; Zhu, C.; Wan, Y. 848 Fractionation of Stable Cadmium Isotopes in the Cadmium Tolerant 849 Ricinus communis and Hyperaccumulator Solanum nigrum. Sci. Rep. 850 2016, 6, 24309.

(62) Lacan, F.; Francois, R.; Ji, Y.; Sherrell, R. M. Cadmium isotopic 852 composition in the ocean. Geochim. Cosmochim. Acta 2006, 70 (20), 853 5104-5118.

854

(63) Yang, S.-C.; Lee, D.-C.; Ho, T.-Y. Cd isotopic composition in 855 the suspended and sinking particles of the surface water of the South 856 China Sea: The effects of biotic activities. Earth Planet. Sci. Lett. 2015, 857 $428,63-72$.

(64) Zhang, Y.; Wen, H.; Zhu, C.; Fan, H.; Luo, C.; Liu, J.; Cloquet, 859 C. Cd isotope fractionation during simulated and natural weathering. 860 Environ. Pollut. 2016, 216, 9-17.

(65) Weinstein, C.; Moynier, F.; Wang, K.; Paniello, R.; Foriel, J.; 862 Catalano, J.; Pichat, S. Isotopic fractionation of $\mathrm{Cu}$ in plants. Chem. 863 Geol. 2011, 286 (3-4), 266-271.

(66) Ryan, B. M.; Kirby, J. K.; Degryse, F.; Harris, H.; McLaughlin, 865 M. J.; Scheiderich, K. Copper speciation and isotopic fractionation in 866 plants: uptake and translocation mechanisms. New Phytol. 2013, 199867 (2), 367-78.

(67) Nicholson, F. A.; Jones, K. C.; Johnston, A. E. Evidence for the 869 Leaching of Surface Deposited Cadmium in Agricultural Soils; 870 Organisation for Economic Cooperation and Development: Paris, 871 France, 1996; pp 218-231.

(68) Nriagu, J. O., Production, uses and properties of cadmium. In 873 Cadmium in the Environment: Part I: Ecological Cycling; Nriagu, J. O., 874 Ed.;John Willey and Sons: New York, 1980. 